\title{
Issues of Existing Pedagogy: Translanguaging as Resources to Enhance Learning at Basic Level in Nepal
}

\author{
Purna Bahadur Kadel \\ purna.kadel@tucded.edu.np \\ Reader \\ Central Department of Education, T.U., Kirtipur
}

\begin{abstract}
Nepal is a multilingual country. Classroom is a miniature of the society. Translanguaging pedagogy is being executed in English as a medium of instruction (EMI) setting in the classroom. This study attempts to investigate the existing pedagogical practices of nonlanguage subjects and to explore the role and impact of translanguaging as resources to enhance learning of non-language subjects' viz. Science, Mathematics and Social Studies at basic level. This is a qualitative study in which phenomenological research design has been adopted to carry out this study. Twelve teachers and thirty students were selected to carry out this study. Semi-structured interview, focus group discussion, and classroom observation were used as tools to collect data. The findings of this study shows that learners' L1 is used as linguistic resources for knowledge construction; there is strong dominance of the ideology of English on them; translanguaging makes the learners involve in interactive classes; they develop critical and creative thinking skills and enhance motivation through translanguaging. It is concluded that mother tongues of the diverse learners could be very effective to be used as a means to understand the content knowledge of non-language subjects in the classroom.
\end{abstract}

Index Terms: miniature, translanguaging, EMI, non-language subjects, and phenomenological research

\section{Introduction}

Nepal is a multilingual, multiethnic, and multi-religious democratic, federal republican country. The primary articulation of language approach in Nepal made in 1905 evidently built up Nepali as the official language of law and government with the statement that as it were records composed in Nepali and legitimate for utilize in courts (Eagle, 1999). Three are many languages spoken in such a diverse country ranging from 92 to 143 languages which are on the verge of disappearance in Nepal (Yonjan-Tamang, 2005). According to CBS (2011), there are 123 languages spoken across the country. All of the languages which have been spoken in Nepal are given the status of national languages in Nepal in the constitution of 2015. Nepali is the main medium of instruction and official national language which is mother tongue of $44.6 \%$ of the total population (CBS, 2011). 
There are 126 authoritatively recognized castes and ethnic groups with practicing of ten diverse confidence frameworks, viz. Hinduism, Buddhism, Islam, Kirat, Christianity, Prakriti, Bon, Jainism, Bahai and Sikhism (CBS, 2011). There are no exclusively monolingual learners in the class generally in any school across the country. However, there can be the majority and minority learners in the class. In Tamang ethnic community, definitely, there is dominance of Tamang speakers in the class. Likewise, Limbu ethnicity community, Limbu speaking learners are in majority in the class. Brahmin-Chetriya community, Nepali speaking learners outnumbers the non-Nepali speakers in the class. Based on the demographic situation of Nepal, mother-tongued based multilingual education is unlikely to be implemented effectively; however, mother-tongued based multilingual education has been introduced in 2008 in Nepal.

After the restoration of second people's movement in 1990, English a medium of instruction (EMI) was implemented from grade one by most of the institutional schools and same design was followed by government of Nepal by executing EMI from grade on in public schools across the country in 2006 (Sah, 2016). The institutional schools which introduced EMI strictly were able to produce good SLC results in the 2013/14 in Nepal (Baral, 2015). This was the main evidence for the government of Nepal to implement EMI to teach non-languages subjects through English throughout the country from grade one. The EMI policy was implemented to be executed from grade one when the third people's movement was successful in 2006 in Nepal

\section{Review of Literature}

The concept of translanguaging was presented by William (2000) within the setting of WelshEnglish bilingual program which centered on to revitalizing the Welsh language. The term tanslanguaging was to begin by William (1994, 1996 as cited in Mazzaferro, 2018) to allude to an academic hone that supports improvement of language abilities through the synchronous utilize of two languages within the classroom activities. William watched in Welsh revitalization programs where the instructor would attempt and instruct in Welsh whereas students would react to a great extent in English. Some of the time, the language choice would be turned around when the learners would study something in Welsh and the teacher would offer clarification in English. Translanguaging helps to maximize the learners' linguistic resources in the process of problem solving and knowledge construction. Learners' first language is a resource for making meaning (Daniel \& Bacheco, 2016). Learners' L1 is the main source of knowledge to solve the problem in the classroom. Wei (2018) states that translanguaging has demonstrated to be pedagogical practice in a variety of instructive settings where the school language or the language of instruction is distinctive from the language of learners.

There are cognitive and sociocultural preferences of utilizing translanguaging whereas educating substance situated information. Conagarajah (2011) contends translanguaging as a marvel involving frequent movement between shaping a collection or one coordinates linguistic framework. The multilingual learners can utilize their linguistic assets in communicative interaction within the course to get it substance information of non-language subjects (Grin, 2018).Translanguaging incorporates theory of cognitive handling, societal utilize of numerous languages and languages in communicative interaction which endeavor to saddle their multilingual repertoires to upgrade learning (Ballinger, Lyster, Sterzuk, \& Genesee, 2017). 
Stewart and Hansen-Thomas (2016) argue that "many bilingual education researchers are now considering how emergent bilinguals' multiple languages interact with one another in the academic setting" (p.451).The learners can clarify any doubt and issue regarding the content knowledge which they shares among their peers based on their linguistic repertoires in addition to English language in the class. The learners can grasp the content knowledge of Mathematics, Science, and social Studies and other non-language subjects better than in English (Khati, 2016). In this regard, the cross linguistic interactional and instructional practices are to be adopted in the multilingual educational environment. In order to make classroom pedagogy learners' friendly, the teachers should have positive perspectives on the learners' bilingualism in the classroom (Stewart \& Hasen-Thomas, 2016).

The use of leaners' L1 and target language in the classroom help to familiarize with the content knowledge and knowledge of the target language. In this regard, Mahmud (2018) asserts that the use of the mother tongues of the learners in the EMI classroom is the verification of learning the content knowledge. It changes the power relations and focus on the method of instructing and learning in making meaning, upgrading, and creating personality (Garcia, 2009; Creese \& Blackledge, 2015).In translanguaging, diverse linguistic repertoires are used in the process of knowledge construction in course of holding discussion and interaction among the learners and teacher to solve the problem in the class. Translanguaging pedagogy help the learners develop their creative and critical thinking skills (Garcia, 2009; Creese \& Blackledge, 2015). Wei, (2018, p. 16) argues that "translanguaging pedagogy also helps to reexamine an old question of the role of L1 in second, foreign, and additional languages teaching and learning". It is utilizing one's idiolect that's one's linguistic collection without respect for socially and politically characterized language. Sharma (2006) states that the use of L1 is to be judicious as long as it facilitates learning English effectively. Translanguaging pedagogy enables the learners to modify their sociocultural identities and values (Garcia \& Wei, 2014). Translanguaging incorporates codeswitching, translating and language brokering or interpreting between culturally diverse individuals (Tse, 1996, as cited in Daniel \& Bachece, 2016).

There are Unitary Translanguaging Theory (UTT) and Crosslinguistic Translanguaging Theory (CTT) which have distinctive concepts of linguistic system (Garcia \& Lin, 2017). Agreeing to UTT, languages have no linguistic or cognitive reality and multilingual linguistic system is unitary and undifferentiated. However, CTT claims that multilingual learners talk different languages including multiple registers, lexicons, and syntacticstructures. There is plausibility of conceptual and linguistic transfer across the language through translanguaging. Both CTT and UTT acknowledge the multilingual cognitive working and translanguagingpedagogy as a central component for social justice and equity in education. Cross Translanguaging Theory has pointed out the following outlines for teachers in the classroom:

- To engage and valorize students' multilingual repertoires, including their home varieties of L1 and or L2,

- To reinforce students' grasp of academic language across the curriculum,

- To maximize students' active engagement with listening and,

- To affirm students' emerging identities as cognitively and academically capable multilingual. 
Translanguaging conceptualizes language as a multilingual, multisemiotic, multisensory, and multimodal asset for sense and meaning making. Translanguaging creates a social space for the language user by bringing together different dimensions of their personal histories, experiences, their attitudes, beliefs and ideologies cognitive and physical capacity into one coordinated and meaningful performance ( $\mathrm{Li}, 2011 \mathrm{a})$. The learners can share their experiential learning, narrative story of different experiences and their beliefs and faiths while holding discussion and interaction in the class.

It is accepted that English is the vehicle of school education to teach non-language subjects through English as a medium of instruction (EMI) which has been progressively famous in the outer and expanding circle nations. It was accounted for that there is uplifting outlooks of utilizing EMI from the students and educators point of views (Ball \& Lindsay, 2013; Costa \& Coleman, 2013; Tong \& Shi, 2012) because students get more freedoms to have conversation and collaboration of significance arrangement of EMI. The real courses are to be needed to make EMI programs compelling and fruitful. To address the difficulties of economic globalization and mechanical disruption, the overall courses and subject-explicit courses in school training and more significant level instruction are to be educated through English.

There are 3 types of schools as per the demonstrative schools typology within the lights of language utilized in schools. Type 1 schools refer to the schools with homogeneously Nepalispeaking learners on the entry to early childhood educational development (ECED). Type 2 schools contain the learners who talk homogeneously same language other than Nepali as their mother tongues e.g. Newari, Tamang, Gurung, Sherpa, Bantawa, Rai, Limbu, etc. Type 3 schools include learners talking diverse mother tongues heterogeneously in schools (Pradhan, 2020). Due to the diverse language speakers in the classroom, teachers of each subject should adopt tanslanguaging pedagogy to make them clarify the main subject matters. The learners of each ethnic community are to be divided into different groups based on the homogeneity of language while holding discussion and interaction on the different issues of content knowledge in the class.

\section{Statement of Problem}

English as a medium of instruction (EMI) was presented in European universities within the 1990s (Coleman, 2006). English has become the medium of instruction for scholastic subjects such as Science, Mathematics and Social Studies in non-Anglophone countries like Nepal. The main objective of EMI program is to enhance the communication abilities and intercultural relations with native and non-native speakers of English speakers of English (Dearden, 2015). EMI is being executed in basic, secondary, and college levels from the third people's movement in 2006 in Nepal. The number of students in the public schools has been decreasing in every year despite the fact that government of Nepal has been implementing EMI policy strictly by handing over the power of educational policy to the local government across the country. More importantly, the results of Science, Mathematics and Social Studies of class 5, 8 and SEE of the public schools are not as satisfactory as the institutional schools in Nepal. There should be 50, 45, and 40 students in each class in Terai and valley, hill, and Himalaya respectively as per the government policy (Ministry of Education, 2009). However, it is hardly to meet these criteria of 
the government of Nepal though government has appointed qualified teachers of each subject, with formal and systematic monitoring from local, state and federal educational authorities, and required infrastructure in the most of the public schools throughout the country.

\section{Objectives of the Study}

The objectives of this study were as follows:

- To investigate the existing pedagogical practices of non-language subjects (Science, Mathematics and Social Studies) at basiclevel

- To explore the role and impact of translanguagingas resources to enhance learning of nonlanguage subjects viz. Science, Mathematics and Social Studies at basic level

\section{Methodology}

Phenomenology is a form of qualitative research which focuses on the study of an individual's lived experience. It is a research paradigm. Phenomenology is concerned with understanding of social and psychological phenomena from the perspectives of the people. It is about the lived experiences of the people (Litchman, 2006). In phenomenology research, there is capturing of rich description of phenomena that is perceived by the people. The researcher in phenomenology study attempts to understand the world from the subjects' point of views to unfold the meaning of their experiences. The phenomenology provides theoretical guidelines to the researcher to understand phenomena at the level of subjective reality. The nature of phenomenology gives a wider meaning of the lived experiences about the phenomena through consciousness (Creswell, 2011).

Six secondary schools of Kavrepalanchok district were selected through purposive non-random sampling procedure to collect data for this study. I selected 2 teachers of Mathematics, and Science and 5 students from each six schools. I administered semi-structured interview to 12 teachers regarding existing pedagogical practices of teaching Mathematics and Science and application of translanguaging while teaching non-language subjects. I conducted focus group discussion with 5 students of each school to collect data. There were 12 teachers and 30 students altogether 42 participants as sampling for this study. I used focus group discussion, semi-structured interview and classroom observation as tools to collect required data in this study. I observed 12 classes of Mathematics and Science of grades 4, 6, and 8.

\section{Results and Discussions}

Based on the collected data from respondents and classroom observation, 5 global themes were developed out various organized and common themes which have been discussed as below:

L1 as linguistic resources for knowledge. The diverse demographic scenario can be witnessed in the classroom at basic level. The teachers of non-language subjects try their best to deliver their content knowledge in English since EMI has been in practice at public school. Every guardian wants that the teachers of community schools have to teach their children of nonEnglish subjects through EMI. In this regard one of the respondents T1 said 
I am not fluent in English to teach Mathematics. I frequently use main terminology of the particular topic in English. I use broken English while explaining, describing and demonstrating the content to the students. Most of the students are confused with the meaning of the content knowledge when I follow EMI; however when I asked the students who belong to different linguistic communities to share their ideas in their mother tongues. I also helped them using Nepali language to make them understand in their mother tongues. Subsequently, I divide them in terms of homogenous language community. Then, I let them share their ideas to one another in their culture and using their own mother tongues.

It can be inferred that $\mathrm{L} 1$ is the resource of knowledge of the learners which one of their teacher accepted. In the same vein, I conducted the focus group discussion, majority of the students asserted that whenever they are ambivalence to understand the content of Science, Mathematics and Social Studies; they shared the main issue of the content to one another colleagues whose mother tongues are homogenous. In this respect, the T3 stated that "I use EMI to explain the content to the learners. Sometimes, I use formulaic phrases and sentences which are not contextually compatible while teaching Social Studies using EMI".

Though EMI policy of Government of Nepal at basic level is being executed, there is not much of its positive impact on learning of non-language subjects due to the lack of adequate proficiency in grammar, vocabulary, language skills of the subject teachers. In this context, the learners should use their mother tongues to understand the contents of Science, Mathematics etc. since Learners' first language is a linguistic resource for making meaning (Daniel \& Bacheco, 2016). It can be inferred that learners' L1 is the resources of knowledge to construct the meaning in the EMI pedagogy.

Dominance of the ideology of English. There is a miracle of the use of English language in every walk of life in the world. Observing the popularity and inevitability of English language in the world, every guardian prefer teaching their children through EMI not only the English as a compulsory and optional subject but also all the subjects except Nepali in public school. In this regard, one of the respondents T5 stated that "I am also pressurized even by the principal, chairperson and members of the school management committee to follow EMI rigidly while teaching Social Studies, otherwise parents can enroll their children in institutional schools. I am, time and again warned that there can be decreasing of the students in upcoming session, if the EMI is not adopted strictly". There is strong influence of the dominance of English even in basic level. In this regard, I came to know through focus group discussion that majority of students have dreams of learning English rather than the actual content knowledge of Mathematics, Science and Social Studies. In this respect T7 asserted that "Students intend that I should use more English than L1 of the learners particularly Nepal which is the lingua franca and official language in Nepal".

It can be inferred that every learners and their parents want to develop proficiency in English by implementing EMI in teaching of non-language subjects in the class. The main objective of EMI 
program is to enhance the communicative abilities and intercultural relations of students with native and non-native speakers of English (Dearden, 2015).

Interactive Classes Using L1 Resources.Due to the low level the proficiency of the student in English, they are reluctant to take part in interaction and discussion either in peer or group discussion in the class. The teachersof non-language subjects do not like to have interaction on the different issues of difficulties of Mathematics, Science and Social Studies subjects owing to the poor proficiency in English. In this regard, one of the respondents T9 said that

when I categorize them into 4 groups on the basis of homogeneity of their mother tongues, whatever I give them the issue to hold discussion and interaction in their mother tongues; they proactively take part in discussion and interaction proactively without any hesitation and uneasiness in the class.

In this respect, the respondent T8 argued that "student can feel relieved when they hold interaction in their mother tongues. They clearly clarify the concept knowledge of the Science and Mathematics when they hold discussion in their mother tongues". Sharma (2006) states the use of L1 is to be judicious as long as it facilitates learning effectively. It is stated that L1 is the main resources of content knowledge. In this regard, the learners can grasp the content knowledge of Mathematics, Science, and social Studies and other non-language subjects better than in English (Khati, 2016). In the classroom, the learners get input regarding the content knowledge in English with their teachers; however they hold interaction among the peers in their own mother tongues.

Developing critical and creative t Skills through translanguaging. The students can develop their critical and creative thinking skills through the practice of translanguaging in the class. The learners can use their higher order thinking skills in course of code switching, translating, and trans-meshing from English to mother tongues and vice-versa in the class. In this regard, one of the respondents T10 argued

I think the learners can apply higher order thinking skills of Bloom Taxonomy viz. analysis, application, and creation in course of holding interaction, discussion, among their homogenous colleagues in the class. In course of switching from English to their mother tongues, they use higher order thinking skills in order to construct the meaning of the content knowledge delivered by the teacher using EMI.

Translanguaging is a very useful pedagogical practice to teach and learn the non-language subjects by multilingual learners with diverse abilities in the classroom. The learners should hold various higher order thinking skills in order to comprehend the given tasks in the class. In this regard, the respondent T11 said that "the students should use their cognitive and meta-cognitive skills in order to analyze the contents delivered in English in their respective mother tongues and report in turn in English to the teacher". Translanguaging helps the learners develop their critical and creative thinking skills in course of applying their L1 linguistic resources to make meaning. 
In this regard, Translanguaging pedagogy help the learners develop their creative and critical thinking skills (Garcia, 2009; Creese \& Blackledge, 2015). From the focus group discussion, the learners get a lot of ideas while translating from English to mother tongues vice-versa and thereby enhancing their critical and creative thinking skills through the translanguaging pedagogy.

Enhancing motivation through translanguaging. The pedagogy of translanguaging really makes the multilingual classroom very interesting and stimulating. The learners are allowed to talk the content delivered in English in their own mother tongues with their colleagues whose mother tongues are similar. In this respect, one of the respondents T11 asserted that

when the learners are asked to have discussion the taught content in their own languages and cultures, they are really motivated with enthusiasm to understand the content with relating their culture and indigenous knowledge. The pedagogy of translanguaging is much inspiring and motivating for the diverse learnerswho hardly understand content knowledge using EMI.

The translanguaging pedagogy really makes the multilingual learners feel enthusiastic and happy in the non-languages subjects in the EMI classroom. Wei (2018) states though school language or the language of instruction is distinctive from the language of learners, they enjoy adopting translanguaging practice in the class. I came to know through the class observation that the learners really felt enjoyment to hold discussion in their own mother tongues rather than in Nepal and English in the class.

\section{Conclusion and implication}

Translanguaging pedagogy in the mode of English medium instruction would be very influential and effective move to improve learning. The non-language subjects such as Mathematics, Science, Social Studies, and other subjects can be taught adopting translanguaging pedagogy at Basic level in which EMI has been implemented since 2006. From the results and discussion, it can be inferred that mother tongues of the diverse learners would be very effective to be used as a means to understand the content knowledge of non-language subjects in the classroom. More importantly, English as a medium of instruction can be made successful of the policy of government of Nepal through the practices of translanguaging pedagogy in school level. The nonlanguage teachers should be given training and workshopon how to implement translanguaging pedagogy in EMI setting by the concerned authority as soon as possible to sort out the issues of existing pedagogy in EMI setting.

\section{References}

Ball, P. \& Lindsay, C. (2013). Language demands and support for English medium instruction in tertiary education: Learning from a specific context. In A. Doiz, D. Lasagabaster, \& J. M. Sierra (Eds.), English-medium instruction at university: Global challenges (pp.4461). Bristol: U K: Multilingual Matters. 
Ballinger, S., Lyster, R., Sterzuk, A. \& Genesee, F. (2017). Context-appropriate crosslinguistic pedagogy: Considering the role of language status in immersioneducation. Journal of Immersion and Content-Based Language Education, 5(1),30-57. Doi:10.1075/ jicb.5.102bal.

Baral, K. R. (2015).Parents have right to choose medium of instruction: Executive director of NCED. (Bog article). ELT Choutari.Retrieved from http://eltchoutari.com.

Canagarajah, S. (2011).Translanguaging in the classroom: Emerging issues for research and pedagogy. Applied Linguistics Review, 2, 1-28.

Central Bureau of Statistics (2011).National population and housing census, 2011, National Report .Central Bureau of Statistics (CBS). Kathmandu, Nepal.

Coleman, J. A. (2006). English-medium teaching in European higher education. Language Teaching, 39(1), 1-14.

Cook, V. (2008). Second language learning and language teaching. London: Routledge.

Costa, F. \& Coleman, J. A. (2013). A survey of English-medium instruction in Italian education. International Journal of Bilingual Education and Bilingualism, 16, 3-19.

Creese, A. \& Blackledge, A. (2015).Translanguaging and identity in education setting, Annual Review of Applied Linguistics, 35.20-35.

Creswell, J. W. (2011). Educational research: Planning, conducting, and evaluating quantitative and qualitative research. (4th ed.). New Delhi: PHI Learning Pvt. Ltd.

Cummins, J. (in press). Translanguaging: A critical analysis of theoretical claims. In P. Juvonen \& M. Kallkvist (Eds.) Pedagogical translanguaging: Theoretical, methodological and empirical perspectives. Bristol: Multilingual Matters.

Daniel, S. M. \&Bacheco, M. B. (2016). Translanguaging practices and perspectives of four multilingual teens. Journal of Adolescent \& Adult Literacy, 69(6), 653-663.

Dearden, J. (2015). English as a medium of instruction: A growing global phenomenon. London: British Council.

Eagle, S. (1999). The language situation in Nepal. Journal of Multilingual and Multicultural Development, 20(4), 272-327.

Franceschin, R. (2011). Multilingualism and multi-competence: A conceptual view. The Modern Language Journal, 95(3), 344-355.

Garcia, O. \& Lin, A. M. Y. (2017).Translanguaging in bilingual education. In O. Garcia and M. Y. Lin (Eds.), Bilingual and multilingual education, Encyclopedia of Language and Education, 5, 117-130.

Garcia, O. (2009). Bilingual education in the 21 $1^{\text {st }}$ century: A global perspective. Wiley.

Garcia, O., \& Wei, L. (2014).Translanguaging: Language bilingualism and education. New York: Palgrave Pivot. 
Grin, F. (2018). On some fashionable terms in multilingualism research: Critical assessment and implication for language policy. In P. A. Kraus and F. Grin (Eds.), The politics of multilingualism: Europeanisation, globalization and linguistic governance (pp. 247273) John Benjamins Publishing Company.

Khati, A. R. (2016). English as a medium of instruction: My experience from hinterland. Journal of NELTA, 21(1-2), 23-30.

Li, E. (2011a). Moment analysis tranlanguaging space: Discursive construction of identities bimultilingual Chinese youth in Britain, Journal of Pragmatics, 43, 1222-35.

Litchman, M. (2006). Qualitative research in education: A user' guide. Thousnd Oaks, CA: Sage.

Mazzferro, G. (2018). Translanguaging as everyday practice. In G. Mazzaferro (Ed.), Translanguaging as everyday practice. (pp. 1-12). Turin, Switzerland: Springer Nature Swizerland A.G. Cham. Lttps://doi.org/10.1007/978-3-319-94851_5

Ministry of Education (2009).School sector reform plan, 2009-2015. Kathmandu, Nepal: Government of Nepal.

Pradhan, U. (2020). Reconstructing the local: Exploring 'a sense of place' in mother-tongue education in Nepal. In Yogendra P. Yadava and Lava Deo Awasthi (Eds.), Perspectives on mother tongue-based multilingual education in Nepal (pp.333-350). Kamaladi, Kathmandu: Nepal Academy.

Sah, P. K. (2016 August). English medium instruction (EMI) in Nepalese education: Potential or problem? ELT Chautari, Retrieved from http://eltchautari.

Stewart, M. A. \& Hansen-Thomas, H. (2016). Sanctioning a space for translanguaging in the secondary English classroom: A case of a transnational youth. Research in the Teaching of English, 50(4), 450-472.

Tong, F. \& Shi, Q. (2012). Chinese-English bilingual education in China: A case study of college science majors. International Journal of Bilingual Education and Bilingualism, 15, 165182.

Wei, L. (2018). Translanguaging as a practical theory. Applied Linguistics, 39(1), 9-30. doi: 10.1093/applin/amx.039.

Weinberg, M. (2013). Revisiting history in language policy: The case of medium of instruction in Nepal. Working Papers in Educational Linguistics (WPEL), 28(1), 61-80.

William, C. (2000). Welsh-medium and bilingual teaching in the further education sector. International Journal of Bilingual Education and Bilingualism, 3(2), 129-148.

Yonjan-Tamang, A. (2012). Bahubhahikshishakokura. Kathmandu, Nepal: Didi Bahini Offset Press. 